\title{
Family medicine continues uptick during annual residency match
}

$\mathrm{W}$ hile Canada's annual residency match indicates that an increasing number of medical students are expressing interest in family medicine, advocates say those rising numbers still aren't adequate to address future demands for primary care.

Roughly $34 \%$ of medical school graduates made family medicine their first choice for residencies during the 2011 residency match conducted by the Canadian Resident Matching Service (CaRMS).

But not all family medicine residencies were filled during the two iterations of the match and there were still 56 vacancies after the second iteration, though that represents an improvement over the 68 vacancies left after the 2010 match.

Of the 3012 spots that were available in the annual CaRMS match, 1256 were for family medicine. Of those, $95.6 \%$ were filled through both iterations.

Ideally, about $40 \%$, or even $50 \%$ of medical school graduates in any given year would be seeking family medicine residencies, says Paul Rainsberry, director of education at the College of Family Physicians of Canada. "If you look at the match numbers of available positions, I think it's roughly $40 \%$ of them are family medicine positions and it would be nice if we had that equivalent amount of interest among the students as their first choice. So that's definitely the direction we've been trying to move," he says, adding that "we're beginning to feel a bit more comfortable."

Although a $40 \%$ or $50 \%$ rate has long been pegged as a desirable level for the number of graduates seeking family medicine residencies, that may not be necessary as a result of changes now occurring within many family practices, some observers say.

Increasingly, primary care responsibilities are being taken up by nonphysicians, such as nurse practitioners and

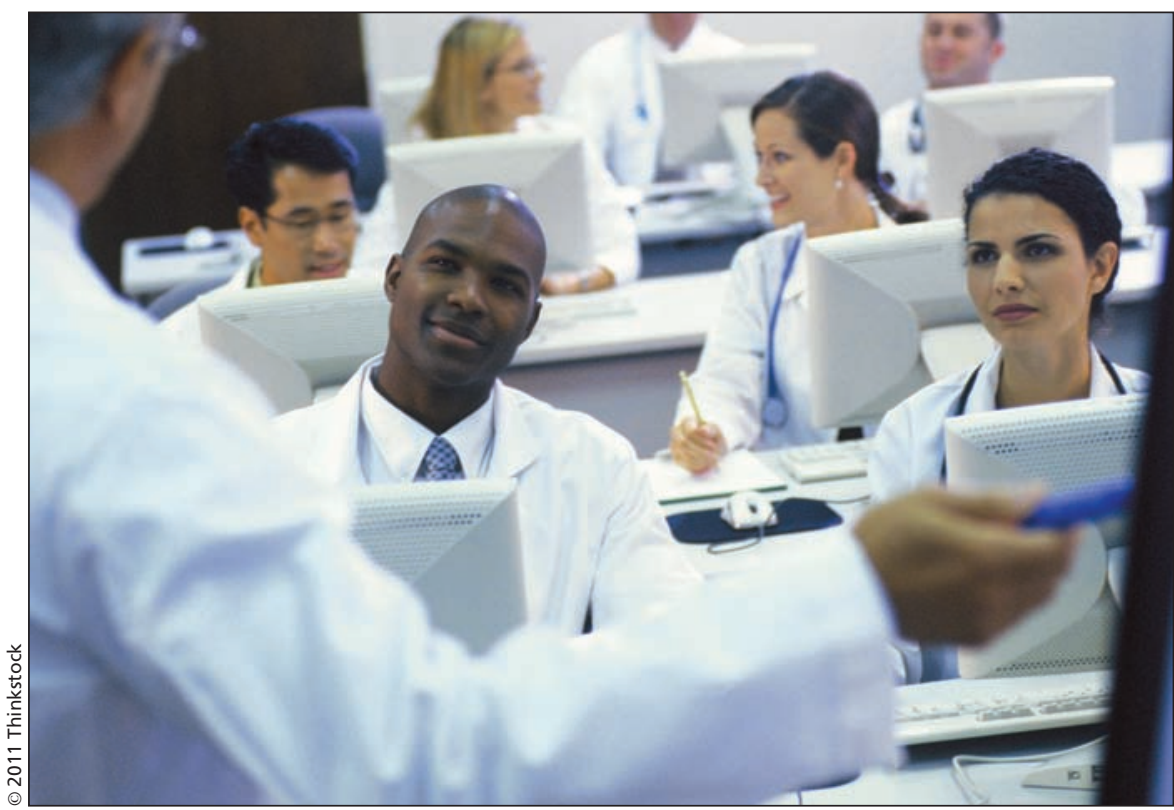

Medical students filled 1200 of 1256 available family medicine residencies in the $\mathbf{2 0 1 1}$ residency match conducted by the Canadian Resident Matching Service.

physician assistants, says Dr. Stephen Tilley, treasurer for the Canadian Association of Residents and Interns. "I think there's going to be more players in primary care than just family physicians so that may very well play into this." But Tilley adds that it is "certainly good to see that there's a rejuvenation in interest in family medicine."

The rejuvenation in interest may be a result of a shrinking in the gap between income levels for family practitioners and specialists in recent years, says Rainsberry. "Funding for family medicine is improving in different provinces so it's becoming more attractive, certainly economically, for people."

The match results also showed that there was no appreciable difference in the percentage of male graduates who expressed an interest in family medicine in the first iteration (27.8\%), but there was close to a $3 \%$ increase in the number of women interested in the field $(38.6 \%)$. There were 1447 female graduates in the first iteration, as compared with 1081 males. By comparison, in 2010, there were 1419 females and 1019 males.

Internal medicine and pediatrics residencies drew the most interest from graduates after family medicine. Some $14.6 \%$ of graduates chose internal medicine as their first priority for a residency, while $6.9 \%$ desired a pediatric placement. Of the 369 Canadian graduates who chose internal medicine as their first choice, all of them got a placement in their area of choice as there were 411 residencies available. On the other hand, only 143 of the 175 applicants for pediatrics were able to secure a residency in that field due to limited placements.

Family medicine once again had the highest number of vacancies, which may be a consequence of there being more positions available than there were qualified candidates at the time of the match, Rainsberry says.

Quebec had the highest number of unfilled family medicine positions after the match, Rainsberry says, speculating that the failure to fill those spots 
may have been a function of a requirement that the successful candidates speak fluent French.

Overall, across all disciplines, $97.3 \%$ of Canadian medical school graduates in 2011 were actually matched. Of the 69 who weren't matched, most had unrealistic career goals and were unwilling to venture far afield, according to the CaRMS match report.

Graduates who were open to opportunities in any location were more successful in achieving a match, which was no surprise as there were 1.1 spots available for every Canadian graduate, Tilley says. "Despite the increases in medical school graduates, that ratio has been preserved."

Tilley also says that Canadian grad- uates are increasingly likely to be matched to their first disciplinary choice. In this year's match, $87 \%$ were matched to their first choice in the first iteration, a slight dip from 2010, but higher than any other year over the last decade.

The residency match continues to operate like clockwork, says Sandra Banner, executive director and chief executive officer of CaRMS. "It's always reliable, the results are very consistent year after year even as we have increasing class sizes, dramatically increased class sizes over the years, it has not altered the results at all."

Banner also notes an increase in the number of international medical graduate applicants. Although there were 1920 applicants this year, up from 1796 in 2010, the number of positions remained at 380 , which is "pretty stiff competition," Banner says.

Tilley says international medical graduates may still be able to find positions across the country, particularly if they are willing to foray to rural parts of Canada. "International medical graduates traditionally have been a great resource for Canada in terms of practising in under-serviced areas," he says, noting that in rural Newfoundland and Labrador, for example, over $50 \%$ of physicians are international medical graduates. "It can be a real win-win if an IMG is willing to go." - Erin Walkinshaw, Ottawa, Ont.

CMAJ 2011. DOI:10.1503/cmaj.109-3952 